\title{
Detection of doxycycline hyclate and oxymetazoline hydrochloride in pharmaceutical preparations via spectrophotometry and microfluidic paper-based analytical device ( $\mu$ PADs)
}

Jwan O. Abdulsattar, ${ }^{1 *}$ Hind Hadi, ${ }^{2}$ Samantha Richardson, ${ }^{3}$ Alexander lles, ${ }^{3}$ and Nicole Pamme ${ }^{3 *}$

${ }^{1}$ Department of Chemistry, College of Science, Mustansiriyah University, Baghdad, Iraq.

2 Department of Chemistry, College of Science, Baghdad University, Baghdad, Iraq.

${ }_{3}^{3}$ Department of Chemistry and Biochemistry, University of Hull, Hull, United Kingdom

Correspondence to: Nicole Pamme (E-mail:n.pamme@hull.ac.uk); Jwan O. Abdulsattar (Email: jwan.abdulsattar@uomustansiriyah.edu.iq)

\begin{abstract}
There is growing demand for simple to operate, sensitive, on-site quantitative assays to investigate concentrations of drug molecules in pharmaceutical preparations for quality assurance. Here, we report on the development of two colorimetric analysis methods for the study the antibiotic doxycycline hyclate (DOX) and the nasal decongestant oxymetazoline hydrochloride (OXY), in solution as well as in their respective formulations. We compare a UV/vis spectrophotometry method with a color change recorded on a microfluidic paper-based analytical device ( $\mu$ PAD). Detection is based on the pharmaceutical compounds coupling with diazotized 4-aminoacetophenone (DAAP) under alkaline conditions to produce colored azo-dye products. These azo compounds were monitored by absorbance at $425 \mathrm{~nm}$ for DOX and $521 \mathrm{~nm}$ for OXY, with linear calibration graphs in the concentration range of $0.5-35 \mathrm{mg} \mathrm{L}^{-1}$ (DOX) and $1.0-40 \mathrm{mg} \mathrm{L}^{-1}$ (OXY) and limits of detection of $0.24 \mathrm{mg} \mathrm{L}^{-1}$ (DOX) and $0.32 \mathrm{mg} \mathrm{L}^{-1}(\mathrm{OXY})$. For the $\mu \mathrm{PAD}$ method, color intensity was measured from photographs and a linear increase was observed at concentrations from above approximately $15 \mathrm{mg} \mathrm{L}^{-1}$ for both compounds and up to $35 \mathrm{mg} \mathrm{L}^{-1}$ for DOX and $40 \mathrm{mg} \mathrm{L}^{-1}$ for OXY. The developed methods were also applied to the formulated pharmaceuticals and no interference was found from the excipient. Thus, the paper-based device provides an inexpensive, simple alternative approach for use outside centralized laboratories with semi-quantitative capability.
\end{abstract}

Keywords: Doxycycline hyclate, oxymetazoline hydrochloride, spectrophotometry, microfluidic paper-based analytical device ( $\mu$ PADs), pharmaceutical formulations. 


\section{Introduction}

Production and distribution of quality controlled pharmaceuticals is vital to the treatment and prevention of diseases across the globe. The analysis of active pharmaceutical ingredients (APIs) is considered as a key part of this process ${ }^{1,2}$. Hence, there is a need for the development of rapid and deployable analytical techniques for clinical monitoring and industrial quality control to address the current lack of routine monitoring and poor regulation within the pharmaceutical industry of developing countries such as $\operatorname{Iraq}^{3-5}$. Here, we aim to address these challenges by studying two different pharmaceuticals, namely (i) a broad spectrum antibiotic, doxycycline hyclate (DOX), and (ii) oxymetazoline hydrochloride (OXY), an adrenergic drug used in eye and nose drops.

Doxycycline hyclate is derived from oxytetracycline or metacycline ${ }^{6}$, with activity against a wide range of gram-positive and gram-negative organisms. ${ }^{7}$ It is commonly prescribed in case of respiratory, skin and soft tissue infection as well as the treatment of sexually transmitted infections ${ }^{8}$ and is also employed to treat infection in veterinary medicine. ${ }^{9}$ Various methods for the determination of DOX concentration in vitro and in vivo have been reported ${ }^{10-15}$ (table S1). Typically traditional laboratory-based techniques, such as high performance liquid chromatograph (HPLC) with spectroscopy detection are employed, which have the potential to achieve sub-mg $\mathrm{L}^{-1}$ sensitivity. For the determination of DOX concentration in pharmaceutical tablets, an HPLC method with UV/vis absorbance detection was developed achieving a limit of detection (LOD) and limit of quantification (LOQ) of 2.8 and $8.6 \mathrm{mg} \mathrm{L}^{-1}$, respectively. ${ }^{16}$ Spectroscopic methods have also been developed such as using UV/vis absorbance detection of the compound in $\mathrm{HCl}$ and $\mathrm{NaOH}$ solutions, achieving sensitivities of 0.3 and $0.2 \mathrm{mg} \mathrm{L}^{-1}$, respectively. ${ }^{15}$ In a further reported spectroscopic method, DOX was reacted with sodium nitrite and benzocaine in an alkaline medium to produce a yellow -orange azo-dye complex, achieving an LOD of $0.42 \mathrm{mg} \mathrm{L}^{-1} .{ }^{17}$ 
Oxymetazoline hydrochloride (OXY), is an imidazoline derivative often used as a decongestant. It is a non-selective adrenergic drug and used in eye and nose drops. ${ }^{18}$ Several analytical techniques have been used for the determination of OXY concentration $^{19}$ (table S2). High performance liquid chromatography ${ }^{20}$ is typically favored, achieving low sensitivity with LODs of sub $\mathrm{mg} \mathrm{L}^{-1} .{ }^{21}$ Flow injection have also been investigated. Since oxymetazoline hydrochloride inhibits the luminol-permanganate reaction under certain conditions, a chemiluminescent flow injection analysis system was developed with an LOD of $1.2 \mu \mathrm{g} \mathrm{L} \mathrm{L}^{-1} .22$

Many of the previously mentioned techniques require sophisticated instruments, expensive reagents, involve several manipulation steps and derivatization reactions. Colorimetric techniques are an attractive alternative and are preferred for routine analytical work for pharmaceutical preparation analysis ${ }^{23-26}$ due to their simplicity and reasonable sensitivity ( $\mathrm{mg} \mathrm{L}^{-1}$ range), along with significant economic advantages. ${ }^{27,28}$ As both compounds, DOX and OXY, have similar chemical structures featuring phenolic groups, they can be reacted with sodium nitrite and a diazonium ion to form brightly colored azo dyes that can be monitored by UV/vis spectroscopy.

Paper-based analytical platforms have recently emerged as an attractive measurement substrate for point-of-need analysis. ${ }^{29,30}$ Typically cellulose filter paper is used, this is low cost and lightweight and can be easily patterned with hydrophobic wax barriers using standard solid wax ink printers ${ }^{31,32}$ to create channels and reaction zones within the paper matrix. Fluid is transported into and through the paper by capillary forces, and where needed reagents can be stored in the porous network. ${ }^{33,}{ }^{34}$ Due to these properties microfluidic paper-based analytical devices ( $\mu$ PADs) have been developed for a variety of applications including health diagnostics ${ }^{35-40}$, environmental monitoring ${ }^{41-45}$, as well as food quality testing. ${ }^{40,46-49}$ Many paper-based devices rely on colorimetric assays as a readout with results gauged by eye or captured by a cell phone camera or scanner and color intensity quantified by computer-based image analysis software. ${ }^{50-52}$ Quantification 
of color intensity is supported by comparison of intensities produced by a known standard solution to an unknown. The paper microfluidic point-of-need analysis approach has the potential to fulfil the World Health Organization (WHO) ASSURED criteria for an ideal rapid test: Affordable, Sensitive, Specific, User-friendly, Rapid and Robust, Equipmentfree, Deliverable to end-user. ${ }^{53}$

Here, we investigate derivatization of DOX and OXY with diazotized 4aminoacetophenone (DAAP) to develop simple to use color based analysis method. We have developed this colorimetric method for traditional UV/Vis spectroscopy and then adapted it for use on a paper-based platform to work towards a system that is accessible and affordable for routine analyses of pharmaceuticals.

\section{Experimental}

\section{Apparatus and reagents}

A Shimadzu double beam recording spectrophotometer (UV-VIS 260 digital) was employed for absorbance measurements and the recording of spectra. All chemicals used were of analytical reagent grade. Distilled water was used for the preparation of all aqueous solutions. Pure doxycycline hyclate (DOX) and oxymetazoline hydrochloride (OXY) samples were kindly provided by the State Company for Drug Industries and Medical Appliance (SDI) (Samarra, Iraq). The formulated drugs were obtained from a local pharmacy in Baghdad (Iraq) as Doxycycline ${ }^{\circledR} 100$ mg tablets (Gerot Lannach, Austria) and as Oxymetazoline ${ }^{\circledR} 0.1 \%\left(1 \mathrm{mg} \mathrm{mL}^{-1}\right)$ nasal drops from (Otrivin, GSK).

\section{Preparation of solutions}

Stock solutions of doxycycline hyclate (DOX) and oxymetazoline hydrochloride (OXY) (500 $\mathrm{mg} \mathrm{L}^{-1}$ ) were prepared by dissolving $0.05 \mathrm{~g}$ of each pure drug in $100 \mathrm{~mL}$ distilled water. Working standard solutions were prepared by suitable dilution of the stock standard solution with distilled water. $2 \mathrm{M} \mathrm{NaOH}$ was prepared by dissolving $20 \mathrm{~g}$ of $\mathrm{NaOH}$ (Merck) in $250 \mathrm{~mL}$ distilled water, and working solutions were prepared by appropriate dilution with the same solvent. Diazotized 4-aminoacetophenone (DAAP) solution $\left(5 \times 10^{-3} \mathrm{M}\right)$ was 
prepared daily by dissolving $0.0675 \mathrm{~g}$ of 4-aminoacetophenone (Merck) in $5 \mathrm{~mL}$ ethanol, $20 \mathrm{~mL}$ distilled water and $2 \mathrm{~mL}$ of $0.8 \mathrm{M}$ hydrochloric acid (Merck, 37\% w/v) in a $100 \mathrm{~mL}$ volumetric flask. The mixture was cooled to $0-5{ }^{\circ} \mathrm{C}$ for 5 min using an ice-bath. Then $0.0345 \mathrm{~g}$ of sodium nitrite (Fluka) was added and the mixture was stirred. After $5 \mathrm{~min}$, the volume was made up to the mark with the addition of cooled distilled water.

\section{Analysis of commercial dosage forms}

DOX-containing powder tablets (100 mg DOX per tablet) were dissolved in distilled water and made up in a $100 \mathrm{~mL}$ volumetric flask and filtered to yield a $500 \mathrm{mg} \mathrm{L}^{-1}$ solution. This stock solution was diluted as required with distilled water. For OXY, a solution of $500 \mathrm{mg}$ $\mathrm{L}^{-1}$ was prepared by diluting the over the counter drug with distilled water and diluted as required with distilled water.

\section{Spectrophotometric detection of DOX and OXY}

Into a series of $10 \mathrm{~mL}$ volumetric flasks, an increasing volume of DOX and OXY working solutions were transferred to cover the range of calibration concentrations. Then $1 \mathrm{~mL}$ of DAAP $(5 \mathrm{mM})$ and $0.5 \mathrm{~mL}$ of $\mathrm{NaOH}(0.2 \mathrm{M})$ was added. The solutions were diluted to the mark with distilled water, mixed and then left for $10 \mathrm{~min}$ at room temperature $\left(25^{\circ} \mathrm{C}\right)$ to allow the color to develop. The absorbance was measured at $425 \mathrm{~nm}$ and $521 \mathrm{~nm}$ for DOX and $\mathrm{OXY}$, respectively, relative to the reagent blanks prepared in the same way containing no drugs. Calibration graphs were produced and regression equations were calculated. For the optimization of conditions and in all subsequent experiments were carried out on $15 \mathrm{mg} \mathrm{L}^{-1}$ of DOX and OXY. Three repeats were carried out for each optimization and calibration experiment, this was achieved by taking three readings for each individual set of conditions investigated. Error bars were calculated using the standard deviation of the three reading. 


\section{Colorimetric detection on $\mu$ PAD platform}

Paper device fabrication The devices were designed using AutoCAD 2016 software and printed onto Whatman Grade 1 filter paper using a Xerox ColorQube 8570 wax printer with ColorQube wax inks as described by Carrilho et al. ${ }^{54}$ Adapting a method from Peters et $a l^{55}$, the wax printed sheets were passed through a laminator (Fellows, model Callisto A4) three times at $125^{\circ} \mathrm{C}$. This allowed the wax to melt and flow through the porous paper to form a hydrophobic barrier throughout the entire paper thickness. The design featured eight circles, $10 \mathrm{~mm}$ diameter and $8 \mathrm{~mm}$ center to center distance, printed with $0.7 \mathrm{~mm}$ line width in green wax. Each device also included a set of six colored squares as internal standard to account for changes in lighting conditions and camera to camera differences during image analysis.

Assay measurements The microfluidic paper device featured a total of eight circular reaction zones of $10 \mathrm{~mm}$ diameter, thus allowing for eight separate measurements on the same device. The DOX assay was carried out by spotting $5 \mu \mathrm{L}$ of the drug standard solutions, separately into seven of the eight reaction zones on the paper device using a micropipette. One reaction zone was left blank. Next, $5 \mu \mathrm{L}$ of the reagent DAAP ( $5 \mathrm{mM})$ and $5 \mu \mathrm{L}$ of $\mathrm{NaOH}(0.2 \mathrm{M})$ were pipetted into the seven reaction zones. Similarly, for the OXY assay, $5 \mu \mathrm{L}$ of drug solution was pipetted onto the paper, followed by $5 \mu \mathrm{L}$ of base and $5 \mu \mathrm{L}$ of DAAP reagent. After pipetting, the paper devices were left to dry before a photograph was taken using a Samsung note 9 camera phone. Devices used for DOX investigation were photographed 20 min after the sample was added and for OXY after $30 \mathrm{~min}$. The same procedure was also applied for the pharmaceutical samples. Each individual optimization and calibration experiment was repeated either 3 or 4 times detail shown in the figure caption, error bars were produced using the standard deviations of these repeats. 
Image analysis Images were analyzed with ImageJ freeware ${ }^{56}$ (National Institutes of Health, USA, https://imagej.nih.gov/ij/docs/fags.html) (figure S1). Akin to a method published by Boehle et al., ${ }^{57}$ the .jpg images were first inverted. The image was then split into the three separate color channels (RED, GREEN and BLUE), for DOX reaction the BLUE channel was used and for OXY reaction the GREEN channel was used, as this was found to give the largest difference for measurements of varying sample concentrations. The area enclosed by the green wax barrier was analyzed by measuring the mean grey pixel intensity to give an average pixel intensity for each circle. To minimize effects from variations in environmental conditions an internal colored square was included in the PAD design. Average relative intensity (ARI) was obtained by dividing the average pixel intensity (AI) for the individual circles by the average pixel intensity of the yellow (DOX) or pink (OXY) reference square (equation S1). 


\section{Results and discussion}

\section{DOX and OXY measurements via spectrophotometric analysis}

The coupling reaction between DAAP and DOX and OXY leading to the formation of the colored products is shown in Figure 1. Experimentally, yellow and red azo dyes were formed immediately after the addition of dilute aqueous solution of DOX and OXY to DAAP solution in alkaline conditions (around $\mathrm{pH} 12$ ). These remained stable for at least 2 h. The yellow and red products were found to have absorbance maxima at $425 \mathrm{~nm}$ for DOX and at $521 \mathrm{~nm}$ for OXY (Figure S2).

For optimization of the dye-formation reaction, a $15 \mathrm{mg} \mathrm{L}^{-1}$ solution of DOX and/or OXY was employed and absorbance was measured relative to reagents blank at $425 \mathrm{~nm}$ and $521 \mathrm{~nm}$, respectively. Preliminary results indicated that the reaction was $\mathrm{pH}$ dependent, requiring basic conditions to develop a more intense yellow and red color. At basic $\mathrm{pH}$, DOX and OXY form phenoxide anions, and these can readily react with DAAP to form the azo-dye. A range of alkaline solutions (0.2 M), namely sodium hydroxide, ammonium hydroxide and sodium carbonate, were investigated. The results, shown in figure S3, clearly indicated that sodium hydroxide was the most suitable reagent giving the maximum absorbance for both drugs, therefore it was used in all subsequent experiments. 


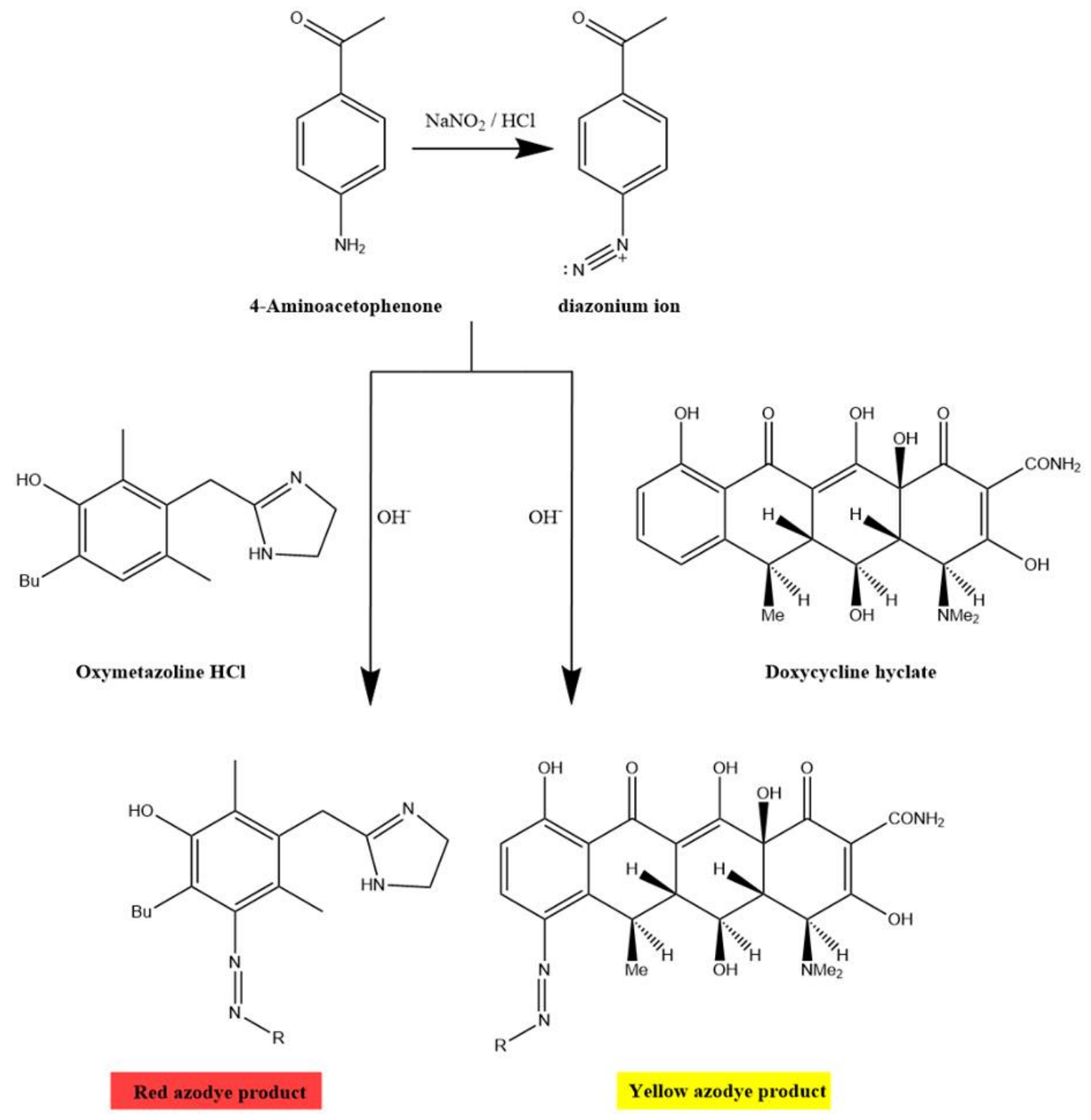

Figure 1: Two step reaction pathway for the formation of azo-dye products, showing 4aminoacetophenone (DAAP) reacting with sodium nitrite under acidic conditions to form a diazonium ion, which then couples with DOX and OXY under alkaline conditions. 
The azo-dye formation for the DOX reaction was further optimized as summarized in Figure 2. Different volumes $(0.25 \mathrm{~mL}$ to $3 \mathrm{~mL}$ ) of sodium hydroxide $(0.2 \mathrm{M})$ were compared (Figure 2a) whilst the other parameters were fixed. It was found that $0.5 \mathrm{~mL}$ gave the strongest color development. Next, the volume of DAAP reagent $(5 \mathrm{mM})$ was varied between $0.5 \mathrm{~mL}$ and $3.0 \mathrm{~mL}$ (Figure $\mathbf{2 b}$ ), and absorbance was found to increase with DAAP volume. Different orders of mixing the drug (D), $\mathrm{NaOH}$ base (B) and DAAP reagent (R) were also examined (Figure 2c). All combinations yielded a similar amount of product, and for future experiments, drug was applied, followed by reagent and base. Finally, the optimum reaction time to readout was investigated (Figure $\mathbf{2 d}$ ). The colored reaction products were visible immediately, but the color intensity increased over time and reached a plateau at around $5 \mathrm{~min}$, which was therefore chosen as the best suited development time. The colored product was found to be stable for at least $90 \mathrm{~min}$ in solution, however a fast readout time is desirable to shorten the workflow.

The same optimization was carried also out for the OXY reaction (Figure 3). The best volume of $\mathrm{NaOH}$ was again found to be $0.5 \mathrm{~mL}$. The volume of DAAP reagent $(5 \mathrm{mM})$ was varied in the range of $0.5 \mathrm{~mL}$ to $2.5 \mathrm{~mL}$, and $1.0 \mathrm{~mL}$ chosen as it gave a high color intensity. The mixing order of OXY followed by based and then DAAP reagent was chosen for future experiments.

After optimization of the different parameters, calibration curves were obtained over the range $0.5-35 \mathrm{mg} \mathrm{L}^{-1}$ for DOX and $1-40 \mathrm{mg} \mathrm{L}^{-1}$ for OXY, respectively (Figure 4). The respective limits of detection and limits of quantification were found to be $0.244 \mathrm{mg} \mathrm{L}^{-1}$ and $0.54 \mathrm{mg} \mathrm{L}^{-1}$ for DOX, and $0.319 \mathrm{mg} \mathrm{L}^{-1}$ and $0.398 \mathrm{mg} \mathrm{L}^{-1}$ for OXY. 
a

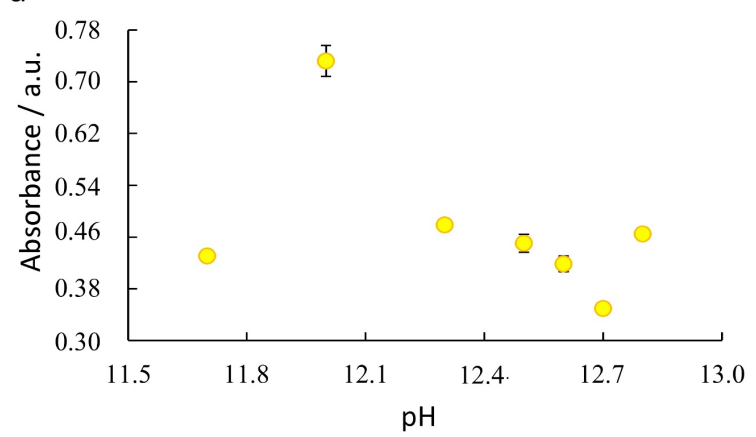

C

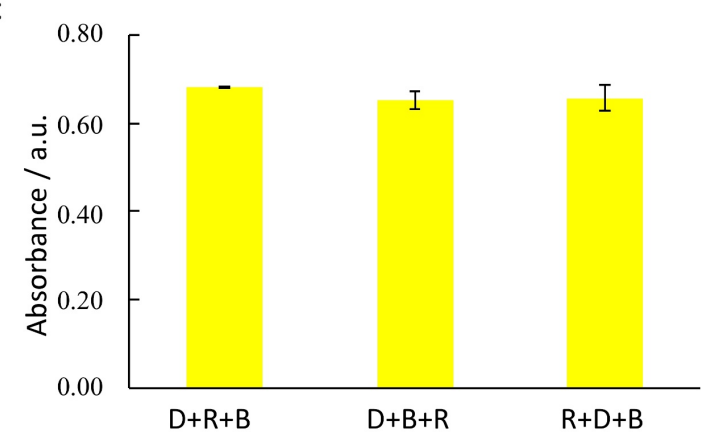

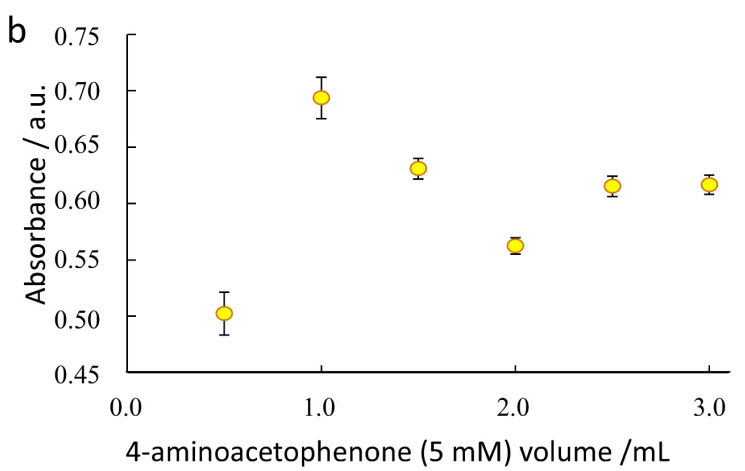

d

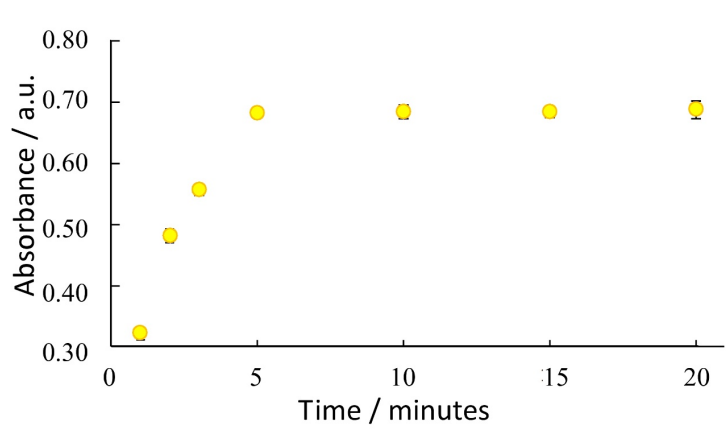

Figure 2: Optimization of reagent parameters for detection of DOX via the formation of a yellow azo-dye complex, all optimization experiments were carried out using $15 \mathrm{mg} \mathrm{L}^{-1}$ DOX solution. (a) The $\mathrm{pH}$ of the prepared solutions was increased by varying $\mathrm{NaOH}(0.2 \mathrm{M})$ between $0.25 \mathrm{~mL}$ and 3 $m L, n=3, R S D \leq 3 \%$, (b) volume DAAP (5 mM) varied between $0.5 \mathrm{~mL}$ and $3.0 \mathrm{~mL}, n=3, R S D \leq 3 \%$. (c) Optimization of reagent addition order, where $D=D O X\left(15 \mathrm{mg} \mathrm{L}^{-1}\right), R=D A A P(5 \mathrm{mM}), B=\mathrm{NaOH}$ $(0.2 \mathrm{M}), n=3, R S D \leq 4 \%$. (d) Development of yellow azo-dye product over time, absorbance recorded between $1 \mathrm{~min}$ and $20 \mathrm{~min}$, showing rapid development of color up to $5 \mathrm{~min}$, then reaching a plateau, where no further development of color occurred, $n=3, R S D \leq 3 \%$. 

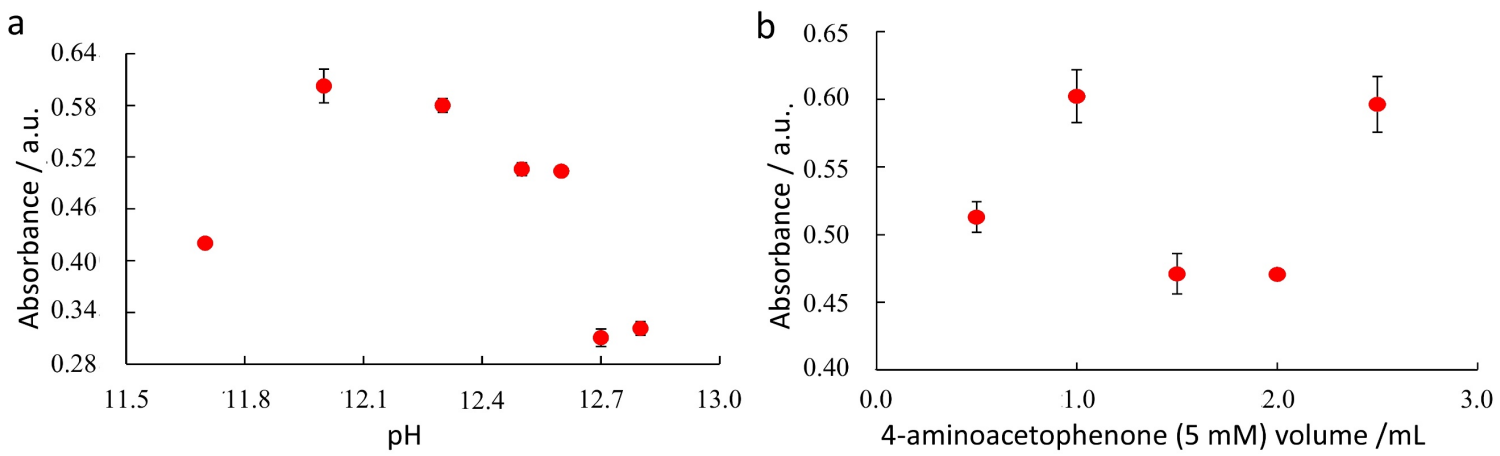

C

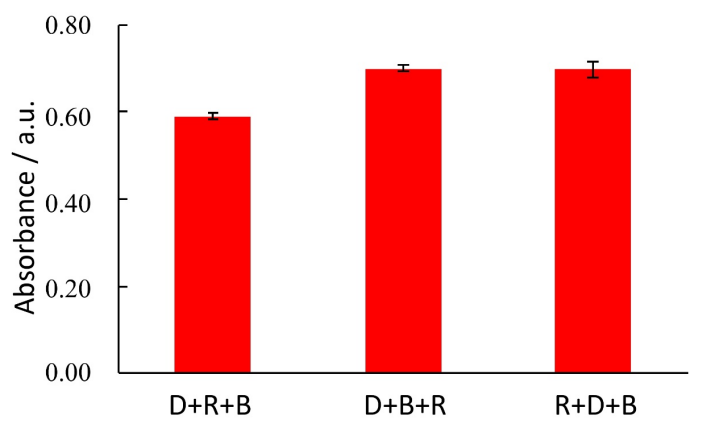

d

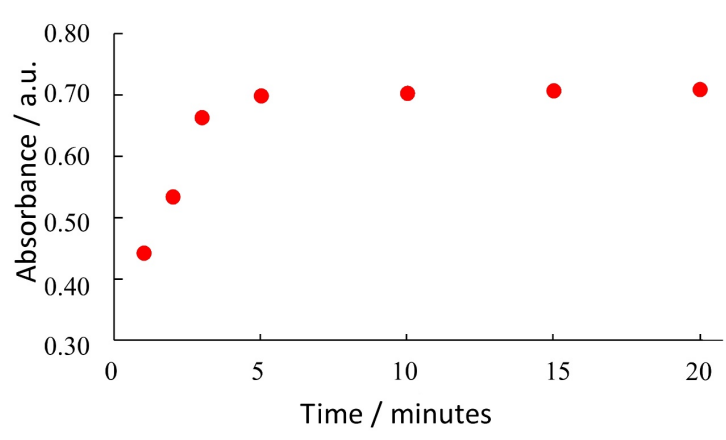

Figure 3: Optimization of reagent parameters for detection of OXY via the formation of a red azo dye complex, all optimization experiments were carried out using $15 \mathrm{mg} \mathrm{L}^{-1}$ OXY solution. (a) The $\mathrm{pH}$ of the prepared solutions was increased by varying $\mathrm{NaOH}(0.2 \mathrm{M})$ between $0.25 \mathrm{~mL}$ and 3 $m L, n=3, R S D \leq 3 \%$. (b) volume DAAP (5 mM) varied between $0.5 \mathrm{~mL}$ and $3.0 \mathrm{~mL}, n=3, R S D \leq 3 \%$. (c) Optimization or reagent addition order were $D=\operatorname{DOX}\left(15 \mathrm{mg} \mathrm{L}^{-1}\right), R=\operatorname{DAAP}(5 \mathrm{mM}), B=\mathrm{NaOH}$ $(0.2 \mathrm{M}), n=3, R S D \leq 3 \%$. (d) Development of red azo-dye product over time, absorbance recorded between $1 \mathrm{~min}$ and $20 \mathrm{~min}$ showing rapid development of color up to $5 \mathrm{~min}$, then reaching a plateau with no further development of color occurring, $n=3, R S D \leq 1 \%$.
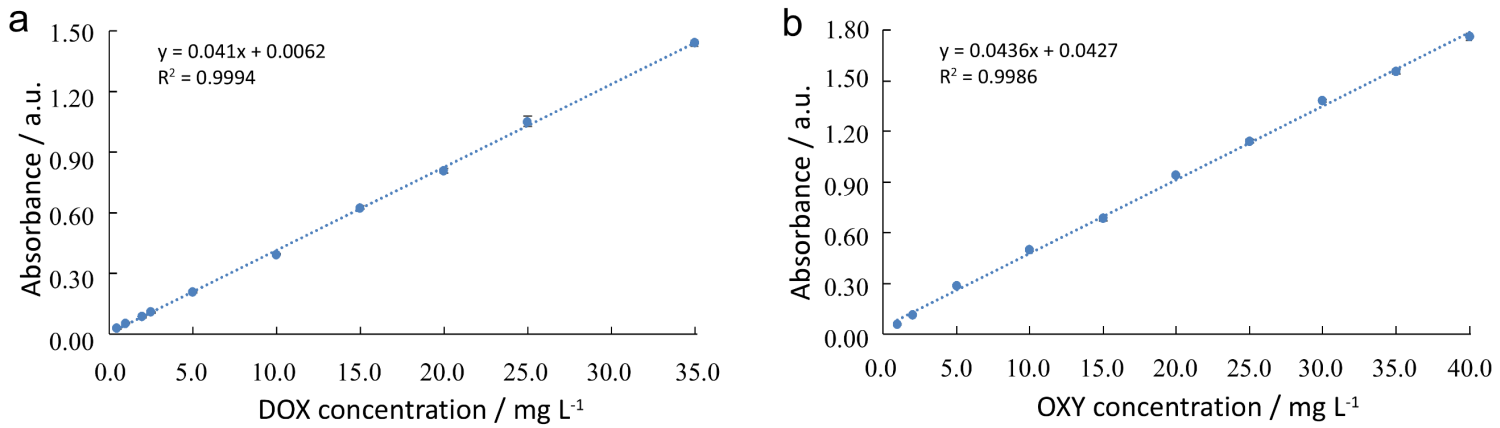

Figure 4: Linear calibration obtained for (a) DOX $\left(0.5-35 \mathrm{mg} \mathrm{L}^{-1}\right)$ and (b) OXY $\left(1-40 \mathrm{mg} \mathrm{L}^{-1}\right), n=$ 3, $R S D \leq 3 \%$. 
DOX and OXY measurements via $\mu$ PADs

The paper microfluidic platform was investigated as an alternative to the conventional laboratory-base spectrophotometer method. The porous matrix of the paper cellulose fibers potentially allows for the storage of reagents, which, when added sequentially would mix to form the azo dye complexes, i.e. a yellow colored complex for DOX and a red colored complex for OXY. This was achieved by adding aqueous reagents to cellulose filter paper that had been patterned with wax to create circular reaction zones within the paper (Figure 5).

a Doxycycline hyclate (DOX)

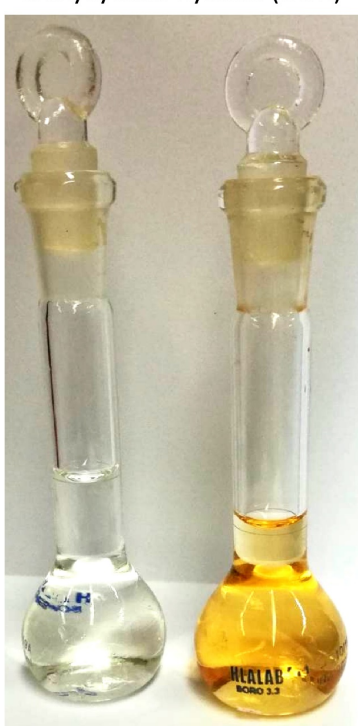

$0 \mathrm{mg} \mathrm{L}^{-1}$

$40 \mathrm{mg} \mathrm{L}^{-1}$ b oxymetazoline $\mathrm{HCl}(\mathrm{OXY})$

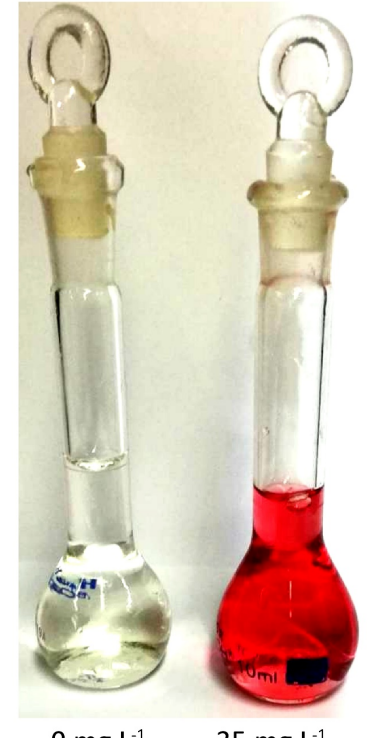

C Paper device (DOX/OXY)
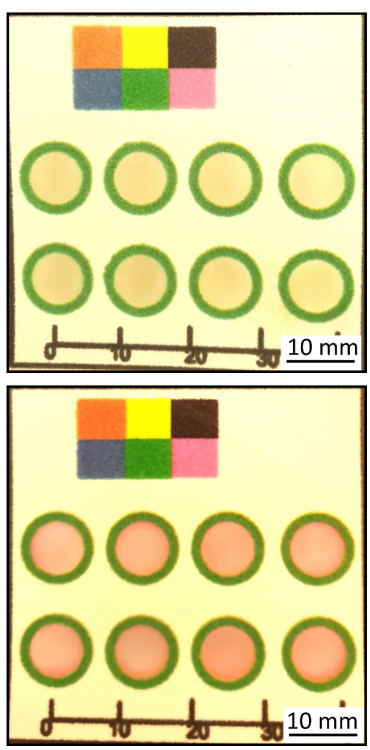

Figure 5: Adaptation of traditional bench top chemistry to paper-based platform. (a) Reaction of DOX (O and $\left.40 \mathrm{mg} \mathrm{L}^{-1}\right)$ with DAAP in alkaline conditions to produce yellow azo-dye. (b) Reaction of DOX (0 and $35 \mathrm{mg} \mathrm{L}^{-1}$ ) with DAAP in alkaline conditions to produce red azo-dye. (c) Reaction performed on paper microfluidic device with reagents and analyte added to the circular reaction zone sequentially. 
Initial studies were performed to optimize the various parameters with a view to establish the maximum color intensity on the paper devices. The influence of varying the volume of the spotted reagents was studied. Insufficient reagent volumes may cause a decrease in intensity, while the excess of addition may lead to reagent leaking out of the sensing zone. The results for the DOX reaction are shown in Figure 6. The $\mathrm{NaOH}(0.2 \mathrm{M})$ volume was varied between $3 \mu \mathrm{L}$ and $9 \mu \mathrm{L}$, as shown in Figure 6a. At $5 \mu \mathrm{L}$, a fairly uniform color distribution of high intensity was observed. The volume of DAAP reagent was also varied in the range of $3 \mu \mathrm{L}$ to $9 \mu \mathrm{L}$ and the color intensity was found to decrease somewhat with an increasing volume of DAAP (Figure 6b). The volume of $5 \mu \mathrm{L}$ was chosen, as it was sufficient to develop even color across the reaction zone without overloading the zone, potentially leading to leakage over the barrier. Next, the addition order of each reagent was studied, similar to previous experiments. For the reaction with DOX the addition order influenced the final result. Figure 6 c clearly shows the importance of adding the DOX solution followed by DAAP and then the base to obtain the greatest sensitivity.

Finally, the reaction time required to obtain maximum and stable intensity was investigated. Previous experiments had shown the reaction progresses quickly in solution reaching a stable color by $5 \mathrm{~min}$. On the paper device, the formed product was measured over the period from 0 to $60 \mathrm{~min}$. As shown in Figure $6 \mathrm{~d}$, the product formation initially increased, with 20 min chosen as best suited development time for the DOX reaction. However, unlike in the solution based methods, the color intensity was found to decrease beyond $40 \mathrm{~min}$, indicating that the product was not stable.

Similarly, the OXY reaction on paper was optimized (Figure 7) and again $5 \mu \mathrm{L}$ was found to be a suitable volume for $\mathrm{NaOH}$. The DAAP volume did not influence the color intensity significantly, suggesting that the reaction was not limited by DAAP volume under the conditions used therefore $5 \mu \mathrm{L}$ was again chosen as it allowed development of an even color across the reaction zone without leakage over the barrier. For the reaction with OXY 
the reagent order addition was not important and had little impact on the final result, as was also seen with the spectroscopic method. The development time of 30 min was chosen for the OXY method as optimum reaction time before images were taken and then further analyzed.
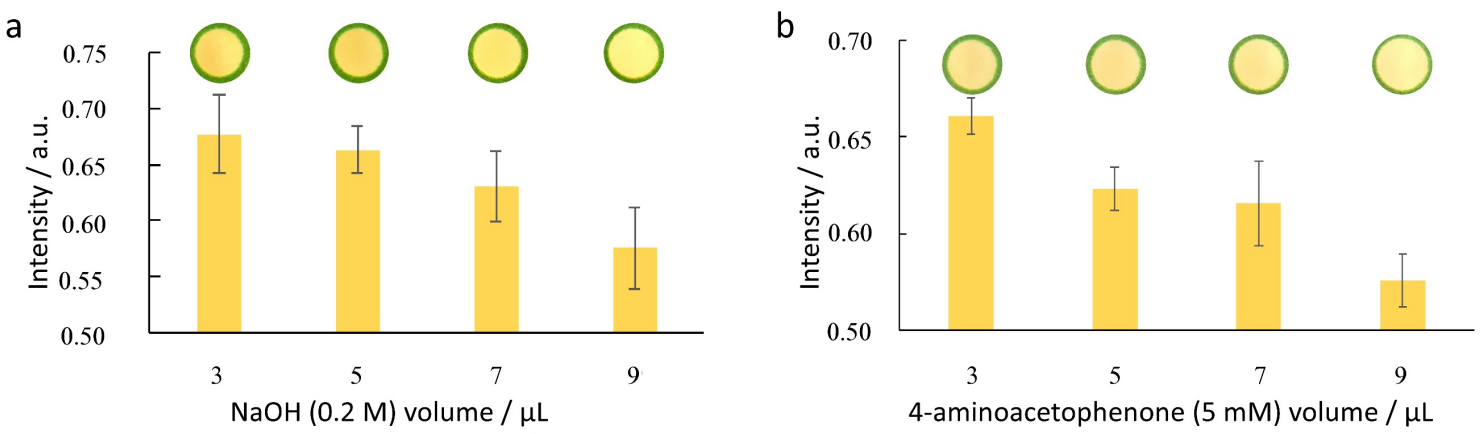

$c$

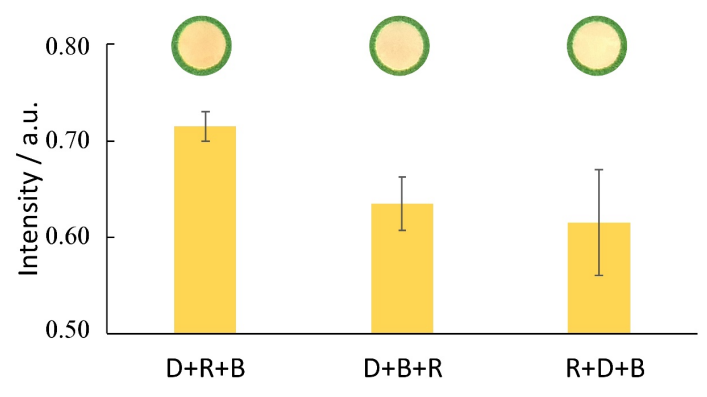

d

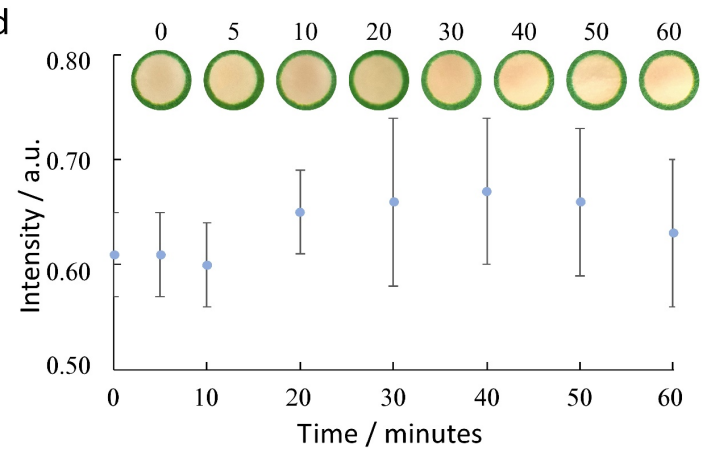

Figure 6: Optimization of reaction parameters for detection of DOX via the formation of a yellow azo-dye on the paper device, all optimization experiments were carried out using $15 \mathrm{mg} \mathrm{L}^{-1} D O X$ solution, $n=3$. (a) Volume of $\mathrm{NaOH}(0.2 \mathrm{M})$ varied between $3 \mu \mathrm{L}$ and $9 \mu \mathrm{L}$. (b) Volume of DAAP reagent ( $5 \mathrm{mM}$ ) varied between $3 \mu \mathrm{L}$ and $9 \mu \mathrm{L}$. (c) Effect of order of reagent addition order with $D$ $=\operatorname{DOX}\left(15 \mathrm{mg} \mathrm{L}^{-1}\right), R=\operatorname{DAAP}(5 \mathrm{mM})$ and $\mathrm{B}=\mathrm{NaOH}(0.2 \mathrm{M})$. (d) Development of yellow azo-dye product over time, absorbance recorded between 0 and $60 \mathrm{~min}$. 
a

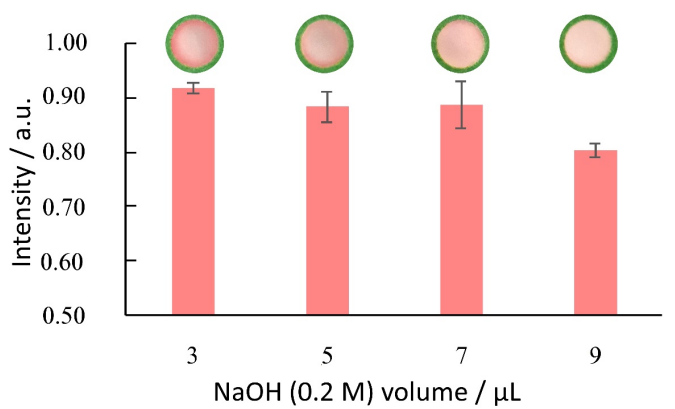

C

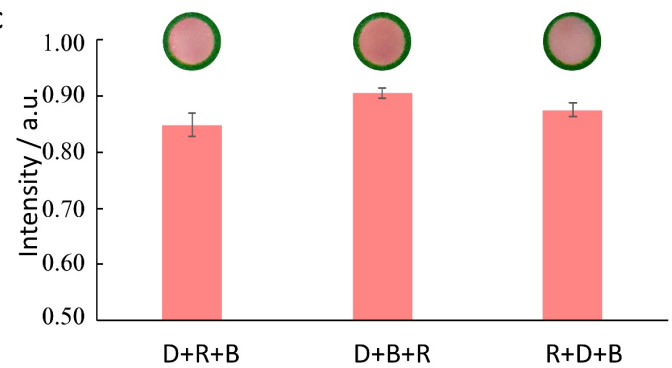

b
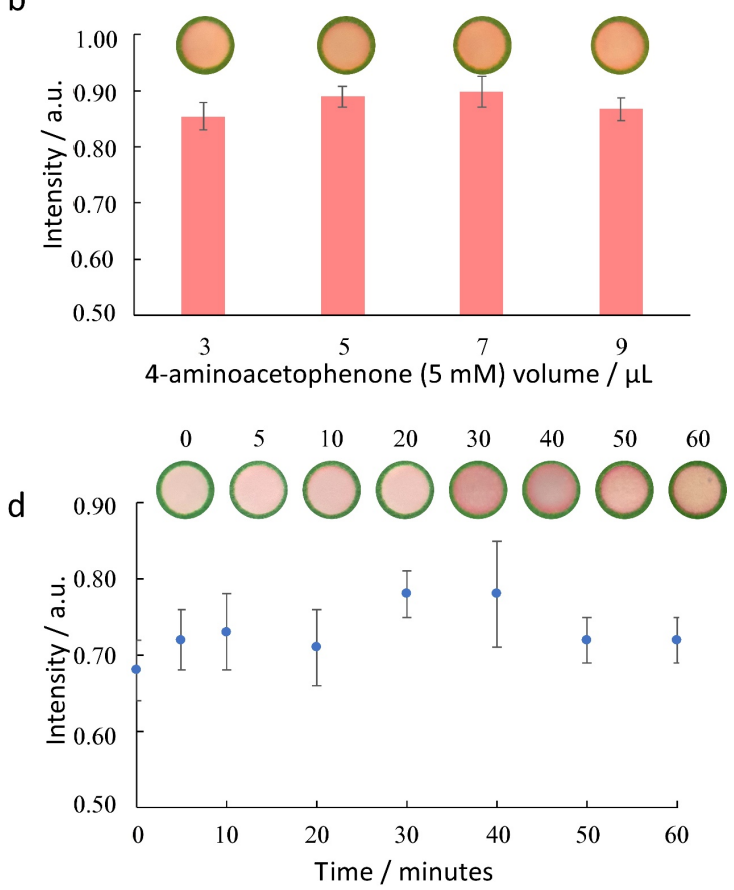

Figure 7: Optimization of reaction parameters for detection of OXY via the formation of a reddish-pink azo-dye on the paper device, all optimization experiments were carried out using 15 $m g L^{-1}$ OXY solution, $n=3$. (a) Volume of $\mathrm{NaOH}(0.2 \mathrm{M})$ varied between $3 \mu \mathrm{L}$ and $9 \mu \mathrm{L}$. (b) Volume of DAAP reagent ( $5 \mathrm{mM}$ ) varied between $3 \mu \mathrm{L}$ and $9 \mu \mathrm{L}$. (c) Study of reagent addition order, where $D=\operatorname{DOX}\left(15 \mathrm{mg} \mathrm{L}^{-1}\right), R=\operatorname{DAAP}(5 \mathrm{mM})$ and $B=\mathrm{NaOH}(0.2 \mathrm{M})$. (d) Development of reddish-pink azodye product over time, absorbance recorded between 0 and $60 \mathrm{~min}$.

Following optimization of the reaction parameters, calibration curves were obtained for DOX $\left(0.5-35 \mathrm{mg} \mathrm{L}^{-1}\right)$ and OXY $\left(1-40 \mathrm{mg} \mathrm{L}^{-1}\right)$ using $5 \mu \mathrm{L}$ of DAAP $(5 \mathrm{mM})$ and $\mathrm{NaOH}(0.2$ M) as shown in Figure 8. Images were captured 20 and 30 min after addition for DOX and OXY, respectively. For both, there was a linear increase in color intensity from drug concentration exceeding $15 \mathrm{mg} \mathrm{L}^{-1}$. At lower concentrations, color intensity was fairly weak and tended to vary, thus this range is not suitable for quantitative determinations. 

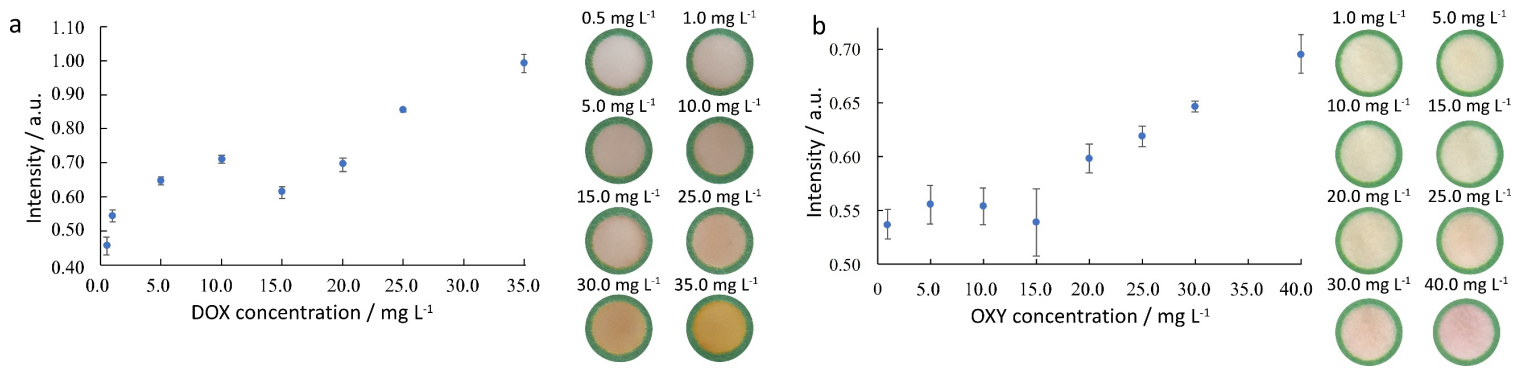

Figure 8: Calibration data showing a linear trend above $15 \mathrm{mg} \mathrm{L}^{-1}$ for (a) DOX (0.5 - $35 \mathrm{mg} \mathrm{L}^{-1}$ ) and (b) $\operatorname{OXY}\left(1-40 \mathrm{mg} \mathrm{L}^{-1}\right), n=4$.

\section{Analysis of pharmaceutical dosage forms}

To assess the efficiency of the method and investigate potential interference from the sample matrix of the tablets and nasal drops solution additives, DOX and OXY concentrations within two pharmaceutical products were determined. The products tested were Doxycycline for DOX and Otrivin for OXY, as detailed in the experimental section. The formulations were prepared in two different concentrations and absorbance compared to the calibration curves. The results are summarized in Table 1. Rec.\% refers to the amount of DOX or OXY found in the prepared solution, when analyzed by UV/vis absorption compared to the amount that should be detected, i.e. the stated concentration in the preparation. RSD\% indicates the relative standard deviation of the four repeats. With $\mathrm{RSD} \% \leq 2.2 \%$ and Rec.\% within $\leq 2.2 \%$ to the expected value, the findings indicate a fairly high accuracy and precision of the method. 
Table 1: Analysis via UV/vis absorption of Doxycycline ${ }^{\circledast}$ tablets and Oxymetazoline ${ }^{\circledR}$ Nasal drops diluted to 5 and $10 \mathrm{mg} \mathrm{L}^{-1}$.

\begin{tabular}{|l|c|c|c|c|}
\hline \multirow{2}{*}{ UV/vis Method } & $\begin{array}{c}\text { Concentration } \\
\text { of prepared } \\
\text { solution } \\
\left(\mathbf{m g ~ L}^{-1}\right)\end{array}$ & $\begin{array}{c}\text { Concentration } \\
\text { determined after } \\
\text { analysis } \\
\left(\mathbf{m g ~ L}^{-\mathbf{1}}\right) \mathbf{n}=\mathbf{4}\end{array}$ & Rec.\% & RSD\% \\
\hline Doxycycline ${ }^{\circledR}$ tablets & 5.00 & 4.89 & 97.80 & 2.04 \\
\cline { 2 - 5 } & 10.0 & 10.02 & 100.20 & 1.10 \\
\hline $\begin{array}{l}\text { Oxymetazoline } \\
\text { Nasal drops }\end{array}$ & 5.00 & 5.06 & 101.20 & 2.11 \\
\cline { 2 - 5 } & 10.0 & 9.89 & 98.90 & 1.66 \\
\hline
\end{tabular}

In comparison to UV/vis detection, the paper devices were suitable for semi-quantitative analysis, a linear trend for both was seen above $15 \mathrm{mg} \mathrm{L}^{-1}$. To investigate this with real samples, a $15 \mathrm{mg} \mathrm{L}^{-1}$ solution of DOX and OXY was prepared for the pharmaceutical formulations and compared to a blank sample (figure 9). Both drugs at $15 \mathrm{mg} \mathrm{L}^{-1}$ show a significant difference from the blank sample, OXY at $p=0.001$ and DOX at $p=0.05$.

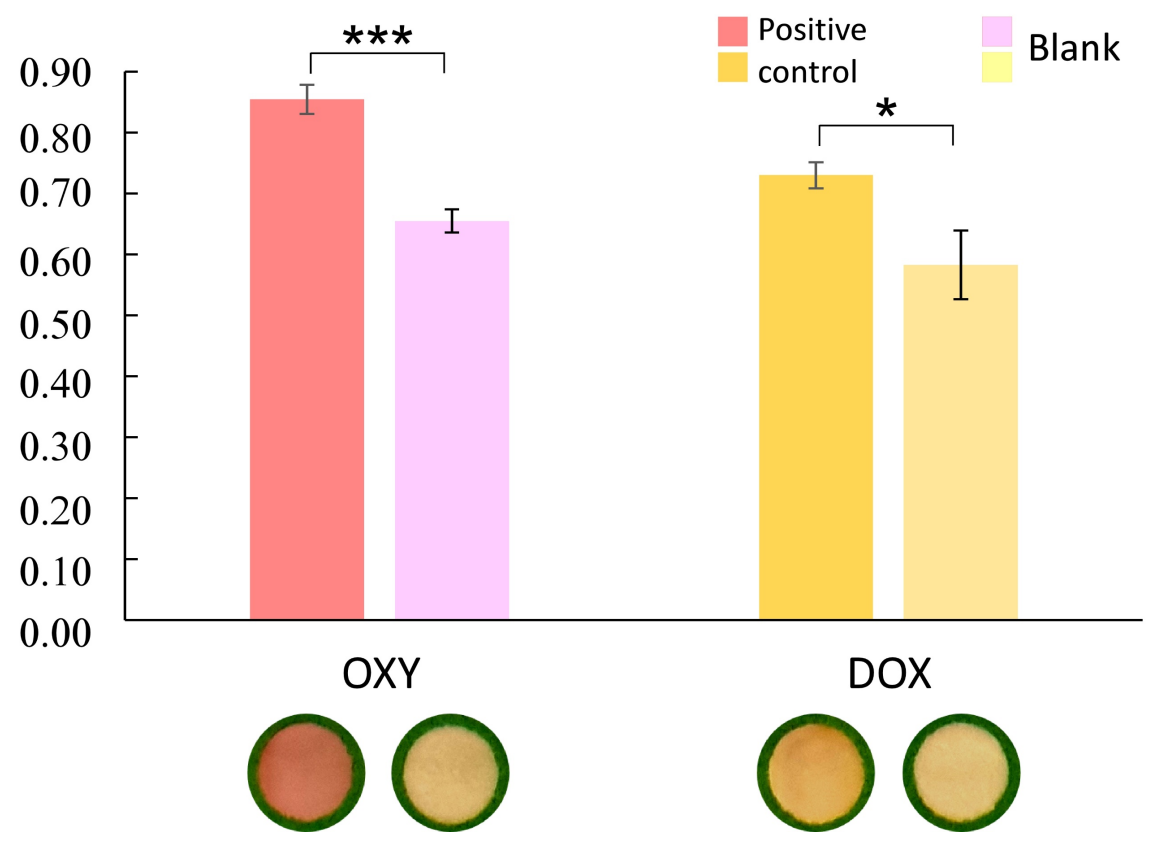

Figure 9: Comparison of a real sample (15 mg L LOX tablets and $15 \mathrm{mg} \mathrm{L}^{-1} \mathrm{OXY}$ from nasal spray with a blank (reagents only). For OXY the positive control and blank were significantly different at 
$p=0.001$, showing equal variance between the two with $F<F_{\text {crit }}(1.5<141.1)$ and 2 tailed $t$ test, assuming equal variance showed significant difference between the two values, $t_{\text {stat }}>t_{\text {crit two-tailed }}$ $(13.1>6.0)$. For DOX the two were significantly different at $p=0.05$, showing unequal variance between the two with $F>F_{\text {crit }}(6.8>9.3)$ and 2 tailed $t$ test, assuming equal variance showed significant difference between the two values, $t_{\text {stat }}>t_{\text {crit two-tailed }}(4.9>2.4), \mathrm{n}=4$.

\section{Conclusion}

We have employed a diazotization reaction for quantitative measurement of DOX and OXY using absorption spectrophotometry. Future work would include widening of types of drugs to be analyzed and a study on the stability of the reaction products, the potential of prestoring the reagents and studying reagent stability over an extended period of time. The paper-based testing device provides an inexpensive, simple and easy-to-use alternative that can be performed outside centralized laboratories with semi-quantitative capability.

\section{Acknowledgement}

Mustansiriya and Baghdad Universities, Iraq are thanked for supporting and providing materials and instruments fundamental for completing this work.

\section{Conflicts of interest}

There are no conflicts to declare.

\section{References}


1. R. Ng, Drugs: from discovery to approval, John Wiley \& Sons, 2015.

2. $\quad$ C. J., The Analysis of Drugs in Biological Fluids 2nd Edition, CRC press, 1995.

3. World Health Organization, Demographic social and health indicators for countries of the Eastern Mediterranean. Cairo, WHO Regional Office for the Eastern Mediterranean., 2013, WHOEM/HST/213/E.

4. T. K. Al-Hilfi, R. Lafta and G. Burnham, Lancet, 2013, 381, 939-948.

5. A. Al-Humadi and C. Liapi, Pharmaceut. Drug Regula. Affair J., 2019, 2, 000116.

6. British Pharmacopoeia, The Stationary Office Ltd, London, 2001.

7. A. L. Cinquina, F. Longo, G. Anastasi, L. Giannetti and R. Cozzani, J. Chromatogr. A, 2003, 987, 227-233.

8. N. Joshi and D. Q. Miller, JAMA Intern. Med., 1997, 157, 1421-1428.

9. J. Fiori, G. Grassigli, P. Filippi, R. Gotti and V. Cavrini, J. Pharmaceut. Biomed., 2005, 37, 979-985.

10. S. M. Sunarić, M. S. Denić, Z. Ž. Bojanić and V. V. Bojanić, J. Chromatogr. B, 2013, 939, 1722.

11. A. Gajda, A. Posyniak, J. Zmudzki and G. Tomczyk, J. Chromatogr. B, 2013, 928, 113-120.

12. B. Gürler, S. P. Özkorucuklu and E. Kır, J. Pharmaceut. Biomed., 2013, 84, 263-268.

13. T. Le, Z. Zhao, W. Wei and D. Bi, Food Chem., 2012, 134, 2442-2446.

14. S. M. Sunaric, S. S. Mitic, G. Z. Miletic, A. N. Pavlovic and D. Naskovic-Djokic, Anal. Chem., 2009, 64, 231-237.

15. P. J. Ramesh, K. Basavaiah, M. R. Divya, N. Rajendraprasad, K. B. Vinay and H. D. Revanasiddappa, J. Anal. Chem., 2011, 66, 482-489.

16. A. C. Kogawa and H. R. N. Salgado, J. chromatogr. sci., 2013, 51, 919-925.

17. R. F. Abbas and A. A. Wheeb, al-mustansiriyah journal of science, 2017, 27, 50-54.

18. F. M. Baroody, D. Brown, L. Gavanescu, M. DeTineo and R. M. Naclerio, J. Allergy Clin. Immunol., 2011, 127, 927-934.

19. N. Wang, Y. Shao, Y. Tang, H. Yin and X. Wu, Luminescence, 2011, 24, 178-182.

20. B. Stanisz and W. Nowinski, Acta poloniae pharmaceutica, 2000, 57, 399-402.

21. S. Sudsakorn, L. Kaplan and D. A. Williams, J. pharma. biomed. anal., 2006, 40, 1273-1280.

22. W. N., S. Y., T. Y., Y. H. and W. X., Luminescence, 2011, 24,, 178-182.

23. S. Ait-Errayess, L. Idrissi and A. Amine, Instrum. Sci. Technol., 2018, 46, 656-675.

24. K. A. Rawat, H. Basu, R. K. Singhal and S. K. Kailasa, RSC Adv., 2015, 5, 19924-19932.

25. J. Khodaveisi, S. Dadfarnia, A. M. H. Shabani and D. Saberi, Sens. Actuators B Chem., 2017, 239, 1300-1306.

26. M. R. Siddiqui, Z. A. Alothman and N. Rahman, Arab. J. Chem., 2017, 10, S1409-S1421.

27. K. A. M. Attia, N. M. El-Abasawi and A. H. Abdelazim, Anal. Methods, 2016, 8, 1798-1805.

28. H. Vakili, J. O. Nyman, N. Genina, M. Preis and N. Sandler, Int. J. Pharm., 2016, 511, 606618.

29. G. G. Morbioli, T. Mazzu-Nascimento, A. M. Stockton and E. Carrilho, Anal. Chim. Acta, 2017, 970, 1-22.

30. A. W. Martinez, S. T. Phillips, M. J. Butte and G. M. Whitesides, Angewandte ChemieInternational Edition, 2007, 46, 1318-1320. 
31. K. Tenda, R. Ota, K. Yamada, T. G. Henares, K. Suzuki and D. Citterio, Micromachines, 2016, 7, 12.

32. Y. Lu, W. W. Shi, L. Jiang, J. H. Qin and B. C. Lin, Electrophoresis, 2009, 30, 1497-1500.

33. T. Akyazi, A. Tudor, D. Diamond, L. Basabe-Desmonts, L. Florea and F. Benito-Lopez, Sens. Actuators B Chem., 2018, 261, 372-378.

34. G. Sriram, M. P. Bhat, P. Patil, U. T. Uthappa, H. Jung, T. Altalhi, T. Kumeria, T. M. Aminabhavi, R. K. Pai and M. D. Kurkuri, TrAC Anal. Chem., 2017, 93, 212-227.

35. T. Tian, X. Wei, S. Jia, R. Zhang, J. Li, Z. Zhu, H. Zhang, Y. Ma, Z. Lin and C. J. Yang, Biosens, 2016, 77, 537-542.

36. M. M. Gong and D. Sinton, Chem. Rev., 2017, 117, 8447-8480.

37. K. Yamada, H. Shibata, K. Suzuki and D. Citterio, Lab Chip, 2017, 17, 1206-1249.

38. L. Magro, B. Jacquelin, C. Escadafal, P. Garneret, A. Kwasiborski, J. Manuguerra, F. Monti, A. Sakuntabhai, J. Vanhomwegen, P. Lafaye and P. Tabeling, Sci. Rep., 2017, 7, 1347.

39. C. E. Majors, C. A. Smith, M. E. Natoli, K. A. Kundrod and R. Richards-Kortum, Lab Chip, 2017, 17, 3351-3387.

40. M. Z. Hua, S. Li, S. Wang and X. Lu, Micromachines, 2018, 9, 32.

41. R. Ota, K. Yamada, K. Suzuki and D. Citterio, Analyst, 2018, 143, 643-653.

42. M. Almeida, B. M. Jayawardane, S. D. Kolev and I. D. McKelvie, Talanta, 2018, 177, 176190.

43. J. Qi, B. Li, X. Wang, Z. Zhang, Z. Wang, J. Han and L. Chen, Sens. Actuators B Chem., 2017, 251, 224-233.

44. J. P. Devadhasan and J. Kim, Sens. Actuators B Chem., 2018, 273, 18-24.

45. X. Sun, B. Li, A. Qi, C. Tian, J. Han, Y. Shi, B. Lin and L. Chen, Talanta, 2018, 178, 426-431.

46. M. Y. Wu, M. Hsu, S. Chen, D. Hwang, T. Yen and C. Cheng, Trends Biotechnol., 2017, 35, 288-300.

47. L. Ma, A. Nilghaz, J. R. Choi, X. Liu and X. Lu, Food Chem., 2018, 246, 437-441.

48. C. Carrell, A. Kava, M. Nguyen, R. Menger, Z. Munshi, Z. Call, M. Nussbaum and C. Henry, Microelectron. Eng., 2019, 206, 45-54.

49. M. Younas, A. Maryam, M. Khan, A. A. Nawaz, S. H. I. Jaffery, M. N. Anwar and L. Ali, Microfluid. Nanofluid., 2019, 23, 38.

50. L. Fu and Y. Wang, TrAC Anal. Chem, 2018, 107, 196-211.

51. N. N. Hamidon, Y. Hong, G. I. J. Salentijn and E. Verpoorte, Anal. Chim. Acta, 2018, 1000, 180-190.

52. N. Lopez-Ruiz, V. F. Curto, M. M. Erenas, F. Benito-Lopez, D. Diamond, A. J. Palma and L. F. Capitan-Vallvey, Anal. Chem., 2014, 86, 9554-9562.

53. W. Y. Lim, B. T. Goh and S. M. Khor, J. Chromatogr. B, 2017, 1060, 424-442.

54. E. Carrilho, A. W. Martinez and G. M. Whitesides, Anal. Chem., 2009, 81, 7091-7095.

55. K. L. Peters, I. Corbin, L. M. Kaufman, K. Zreibe, L. Blanes and B. R. McCord, Anal. Methods, 2015, 7, 63-70.

56. W. S. Rasband, ImageJ, U. S. National Institutes of Health, Bethesda, Maryland, USA, https://imagej.nih.gov/ii/, 1997-2018.

57. K. E. Boehle, J. Gilliand, C. R. Wheeldon, A. Holder, J. A. Adkins, B. J. Geiss, E. P. Ryan and C. S. Henry, Angew. Chem., Int. Ed., 2017, 56, 6886-6890. 